\title{
Low-Frequency Hybrid Earthquakes near a Magma Chamber in Afar: Quantifying Path Effects
}

\author{
by Dustin M. Coté, Manahloh Belachew, Alice C. Quillen, Cynthia J. Ebinger, \\ Derek Keir, Atalay Ayele, and Tim Wright
}

\begin{abstract}
Areas of active volcanism contain elaborate velocity structures that complicate interpretations of earthquake source mechanisms. We examine the spectral characteristics of 805 earthquakes that immediately followed a large volume basaltic dike intrusion and associated silicic flank eruption of Dabbahu volcano in the Afar Depression as recorded on near-source seismometers. We use these results to quantify the contribution of scattering and attenuation to the observed spectra of low-frequency hybrid and volcano-tectonic earthquake clusters from beneath Dabbahu volcano and around the dike zone. We find strong variations in the signal amplitude and frequency content of earthquakes recorded at stations separated by as little as $2 \mathrm{~km}$, caused by preferential attenuation of high frequencies depending on the vantage point. These observations imply that there are large impedance contrasts near the cooling, solidifying, and recently intruded dike. We estimate the intrinsic absorption attenuation coefficient, $Q_{I}$, and inverse scattering length, $g_{0}$, averaged over a 300 -sq-km area beneath Dabbahu. Our results are consistent with the highest attenuation coefficients from studies of volcanic provinces in Italy $\left(Q_{I}^{-1} \approx 0.02, g_{0} \approx 0.1 \mathrm{~km}^{-1}\right.$ for a signal at $2 \mathrm{~Hz}$ ). The magnitude of these two parameters indicates there are large impedance contrasts present in the area due to the recent intrusion of magma and associated fracturing.
\end{abstract}

\section{Introduction}

The frequency spectrum of earthquakes from sources surrounding or within magma chambers and dikes provides insights into magma chamber processes and rock fracture processes, as well as the physical properties of rocks and fluids between the source and the receiver (e.g., Aki, 1992; Chouet, 1996, 2003; McNutt, 2005). Records from seismometers above or near the magma chambers and/or dikes range from impulsive transients to long-lasting tremor (e.g., McNutt, 2005; Neuberg et al., 2006). Some earthquakes may exhibit clear $P$ - and $S$-wave onsets and have peak frequency content in the range of 8-12 Hz. These high-frequency (HF) signals are characteristic of slip during shear fracture. Less commonly, signals may also contain energy between 0.2 and $5 \mathrm{~Hz}$, with or without clear $P$ - and $S$-wave arrivals. These are denoted long-period or low-frequency (LF) earthquakes (Lahr et al., 1994). Throughout this paper, we adopt the usage of LF earthquakes to avoid confusion with traditional long-period seismology. Occasionally, we see a superposition of these two types that are dubbed LF hybrid earthquakes, including earthquakes whose LF component peaks at less than $1 \mathrm{~Hz}$.

Many LF hybrid earthquakes occur in swarms with tectonic earthquakes and show common spectra at a range of receiver distances, pointing to a source process for their anomalous content (e.g., Aki et al., 1977; Brandsdóttir and Einarsson, 1992). Harrington and Brodsky (2007) reproduced observed LF hybrid earthquakes lacking spectral features by assuming low rupture velocities. Cesca et al. (2008) simulated shallow LF hybrids assuming thin volcaniclastic layers at receiver sites and lateral crustal heterogeneities. They found that shallow LF hybrid earthquakes are difficult to classify.

Estimates of attenuation parameters consider the energy at the LF end of the signal as well as the length of the seismic coda. The focus of many earlier, regional studies was in the frequency dependence of the attenuation (e.g., Frankel and Wennerberg, 1987; Giampiccolo et al., 2006). This is the aim of a subsequent work and is not considered here. Instead, we focus on the importance of recognizing the path effects that are critical to earthquake source modeling in regions of magma intrusions and faulting.

We analyze clusters of LF hybrid and tectonic earthquakes recorded on a temporary array deployed three weeks after the intrusion of at least one 6-8-m-wide dike, affecting a 60-km-long rift segment (Wright et al., 2006; Ayele et al., 2007, 2009). We focus on near-source earthquakes within 
$\sim 10 \mathrm{~km}$ of the nearest seismometer and study differences in observed spectra. Multiple magma chambers and the large volume magma intrusion provide a diverse data set of volcano-tectonic earthquakes, and complementary data sets provide constraints on the magma chamber and dike geometries, active faults, and fissures between sources and receivers. The aims of this study are (1) to characterize the spatial distribution of the LF seismicity and relate this to the dikevolcano interaction and (2) to quantify the contribution of attenuation and scattering between source and receiver to the observed signals.

\section{Tectonic Background}

The tectonic-magmatic rifting episode that began in 2005 occurred within the Dabbahu-Manda-Hararo sector of the southern Red Sea rift within the Afar Depression (Barberi and Varet, 1977). This tectonic-magmatic event was accompanied by continuous seismic activity, including tremor, at station FURI in Addis Ababa, ca. $450 \mathrm{~km}$ southwest of the affected area (Yirgu et al., 2006). On 26 September an 600m-long, north-south striking vent opened on the east flank of Dabbahu volcano (Yirgu et al., 2006). The largest of 420 earthquakes recorded between 4 September and 4 October is the $M_{\mathrm{w}} 5.4$ mainshock on 24 September. This intense swarm of earthquakes contained at least 25 earthquakes of $M_{\mathrm{w}} \geq 5.0$ (Ayele et al., 2009). The combined seismic moment is, however, an order of magnitude too small to explain the strain patterns estimated from Interferometric Synthetic Aperture Radar (InSAR) and structural observations (Wright et al., 2006; Rowland et al., 2007; Grandin et al., 2009). Although permanent seismic stations were too distant to analyze the spectral content of the seismicity associated with the dike intrusions, a temporary array was deployed three weeks following diking (Fig. 1).

Satellite geodesy, seismicity, structural, and petrological studies provide clues as to the sources of the magma that fed the dike, as well as the time and space relations for distribution of magma within the crust (Keir et al., 2009). Models of InSAR data indicate that the September-October earthquakes, prior to station deployment, were accompanied by the intrusion of 2-4 dikes spanning $60 \mathrm{~km}$ along strike, with a maximum of an 8-m opening (Wright et al., 2006; Ayele et al., 2007; Grandin et al., 2009). Models of geodetic data indicate that between 1.8 and $2.5 \mathrm{~km}^{3}$ of magma were intruded between 16 September and 4 October 2006 (Wright et al., 2006; Ayele et al., 2007; Grandin et al., 2009). Ayele et al. (2009) used regional stations to relocate the seismicity during the first intrusion, finding that the majority of the dike volume was fed from a reservoir beneath the segment center and propagated northward toward Dabbahu volcano.

A diffuse cluster of postdiking seismicity underlies the broad Dabbahu volcanic complex. Earthquakes form a broad lens of radius $\sim 10 \mathrm{~km}$ at $\sim 2.5-\mathrm{km}$ subsurface. Hypocentral locations surround a sill-like chamber between 3 and $5 \mathrm{~km}$, consistent with estimates from models of InSAR data

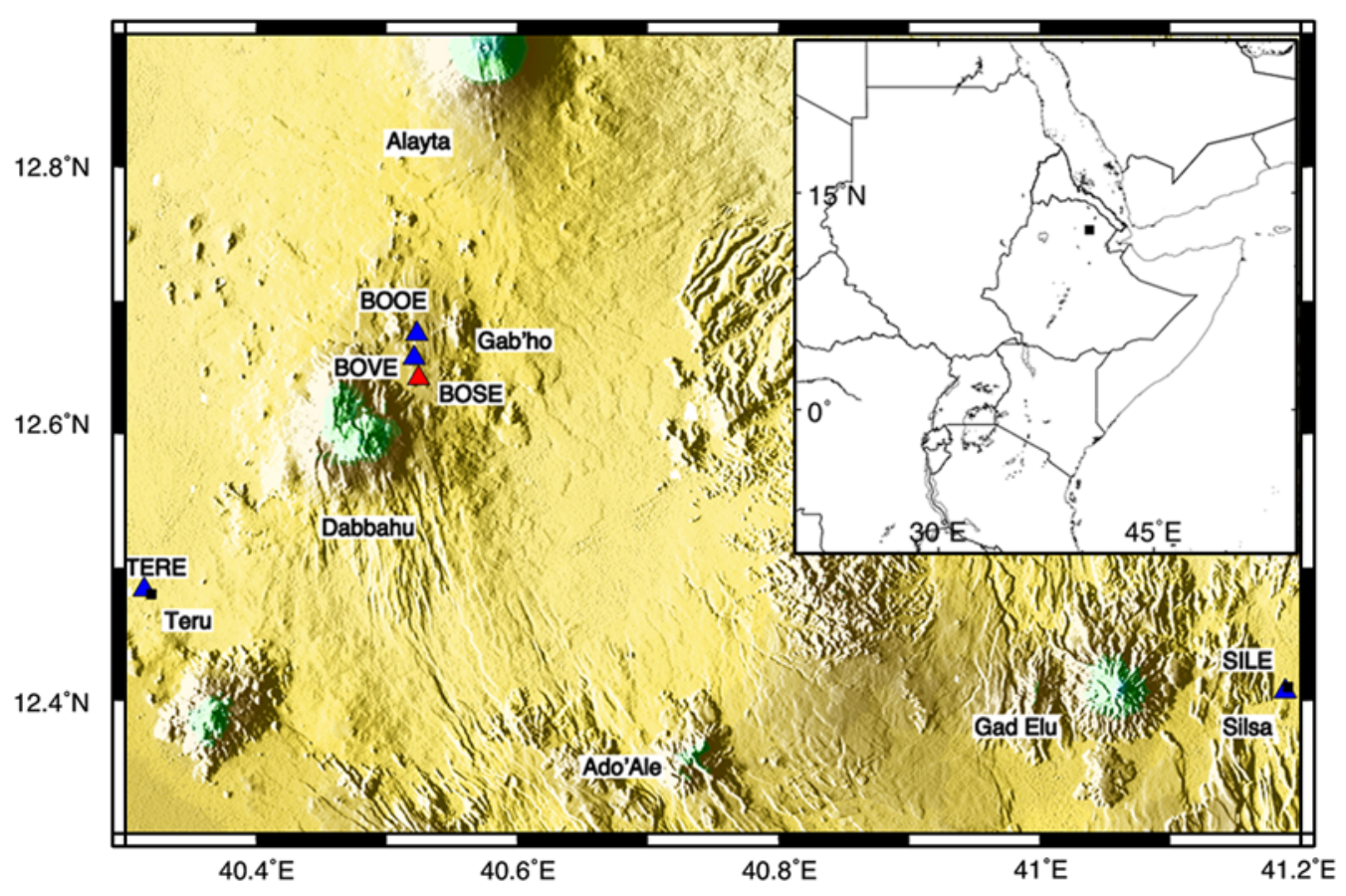

Figure 1. Station layout and surrounding region. Triangles indicate seismic stations, and squares indicate neighboring towns where applicable. BOSE is distinguished due to a malfunction. Major volcanic centers listed are Dabbahu, Alayta, Ado'Ale, and Gad Elu. Shown also is the rhyolitic center Gab'ho near the Da'Ure vent that opened during intrusion. The color version of this figure is available only in the electronic edition. 


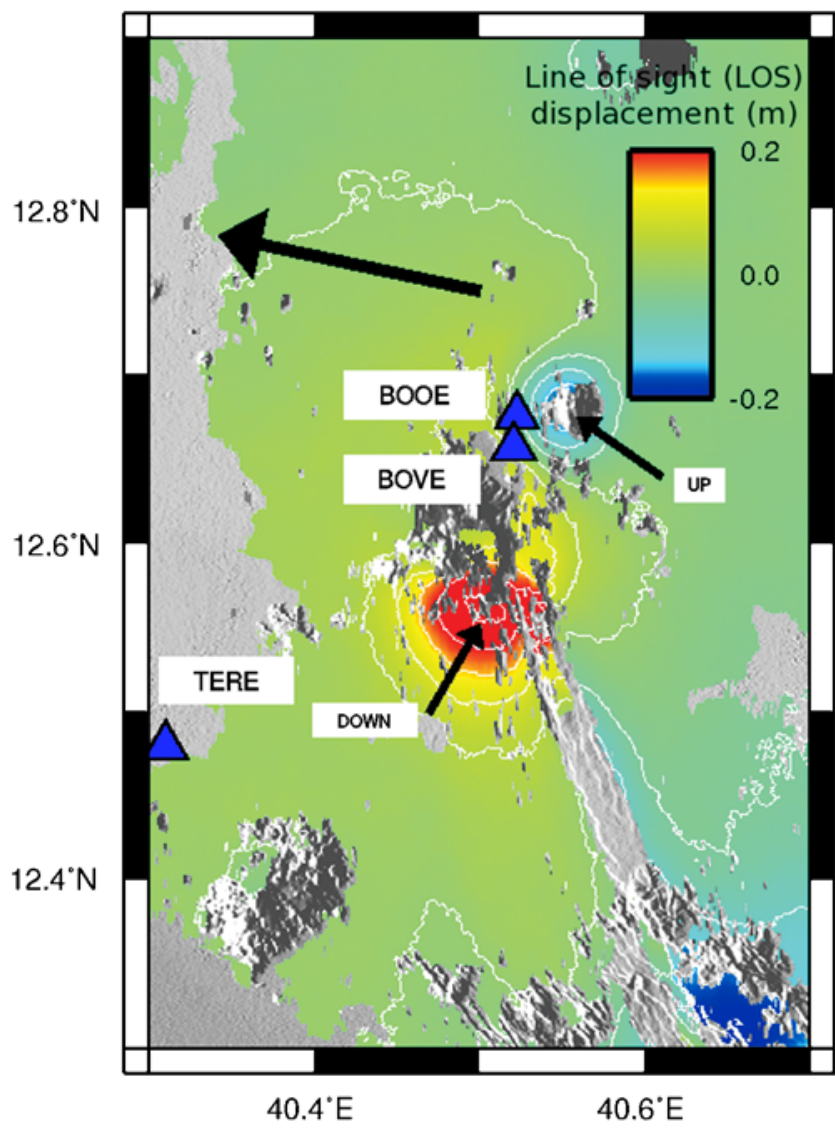

Figure 2. Map showing the line-of-sight displacements occurring between 28 October 2005 and 17 March 2006. Data, copyright European Space Agency (ESA), are from Envisat's standard descending track 49 (mode IS2). The horizontal projection of the look vector is shown by an arrow, and the incidence angle is $23^{\circ}$ from the vertical at BOOE. White contours on displacements are given at $5 \mathrm{~cm}$ intervals; shadows show topography. The centers of Dabbahu and Gab'ho are uplifting during this time period, whereas the southflank of Dabbahu is subsiding as indicated by arrows labeled UP and DOWN, respectively. The color version of this figure is available only in the electronic edition.

(Ebinger et al., 2008). For the first 6 months after the dike intrusion, InSAR data showed $\sim 25 \mathrm{~cm}$ of deflation on the south flank of Dabbahu volcano (Fig. 2). A dense cluster of earthquakes marks the center of this broad zone of subsidence (Ebinger et al., 2008).

Beneath the newly formed vent on the east flank of Dabbahu volcano, Ebinger et al. (2008) observed a 2-kmwide shallow zone ringed by tightly clustered hypocenters, $5 \mathrm{~km}$ below the surface. This halo of seismicity coincides with the source depth for the rhyolitic eruption inferred from models of InSAR data (Wright et al., 2006).

\section{Seismicity Data}

The data set comprises more than 1600 earthquakes with a minimum of eight or more phase pairs recorded on nine Güralp 6TD broadband seismometers during the period
19 October 2005-27 March 2006. Instruments recorded at a sampling rate of $50 \mathrm{~Hz}$ with standard frequency range 0.033-100 Hz. Stations BOOE, BOVE, and BOSE were installed in a linear array flanking the $\sim 600$-m-long vent for a small volume rhyolitic eruption (Fig. 1). BOVE and BOSE lie on the hanging wall and BOOE on the footwall of a westdipping fault that slipped more than $0.5 \mathrm{~m}$ on 26 September (Fig. 3) and exhibited steam emissions immediately following the eruption, suggesting it formed above the dike intrusion (Yirgu et al., 2006, Rowland et al. 2007; Figs. 2 and 3). Estimates of dike freezing times assuming simple conduction for a 4-km-high, 8-m-wide dike are 108 days at $\sim 1-\mathrm{km}$ subsurface (e.g., Turcotte and Schubert, 2002). Thus, the dike zone likely contained melt prior to at least 1 January 2006. We also look at the frequency spectra from TERE, $29 \mathrm{~km}$ southwest of the vent and SILE, $77 \mathrm{~km}$ east of the vent to provide the perspective of alternate azimuths and longer paths (Fig. 1).

The three stations around the eruption site (BOOE, BOVE, and BOSE) show up to 20 well-recorded, shallow volcano-tectonic earthquakes per hour until January 2006 when activity became more episodic. These three stations were all placed a day's walk from dirt tracks, whereas the other stations in this study were in small villages where noise levels are significantly higher. However, the harsh field conditions and rapid deployment caused a GPS failure at BOSE that led to timing errors and hard-disk failure at BOOE in early January 2006. BOSE was redeployed in January 2006. For these reasons we focus on data from October to December 2005. The timing problem at BOSE prevents direct analysis over this period, but manual analysis of larger earthquakes shows no indication of a difference in observed spectral content between BOSE and BOVE.

Earthquakes were initially located using Hypo2000 (Klein, 2000) with average absolute uncertainties in horizontal and vertical position of 1 and $2 \mathrm{~km}$, respectively. Earthquakes were then relocated using the double-differencing method of Waldhauser and Ellsworth (2000). We use 805 earthquakes with relative depth uncertainties estimated to be less than $500 \mathrm{~m}$ and relative horizontal location uncertainties less than $50 \mathrm{~m}$ around Dabbahu (Ebinger et al. 2008). As a measure of absolute uncertainties, we see no horizontal shift in the earthquake clustering between double-difference locations and absolute locations.

\section{Data Analyses}

We focus on the spectral properties of the best-located earthquakes on and around Dabbahu volcano between 22 October and 29 December 2005, allowing us to evaluate the spectral content of shallow earthquakes (e.g., Cesca et al., 2008). Eyewitness accounts, satellite geodesy, and structural analyses provide valuable information about the faulting and diking activity during this time. We use spatial changes in signal properties to establish which zones contain attenuating bodies. With these independent geological constraints, we 


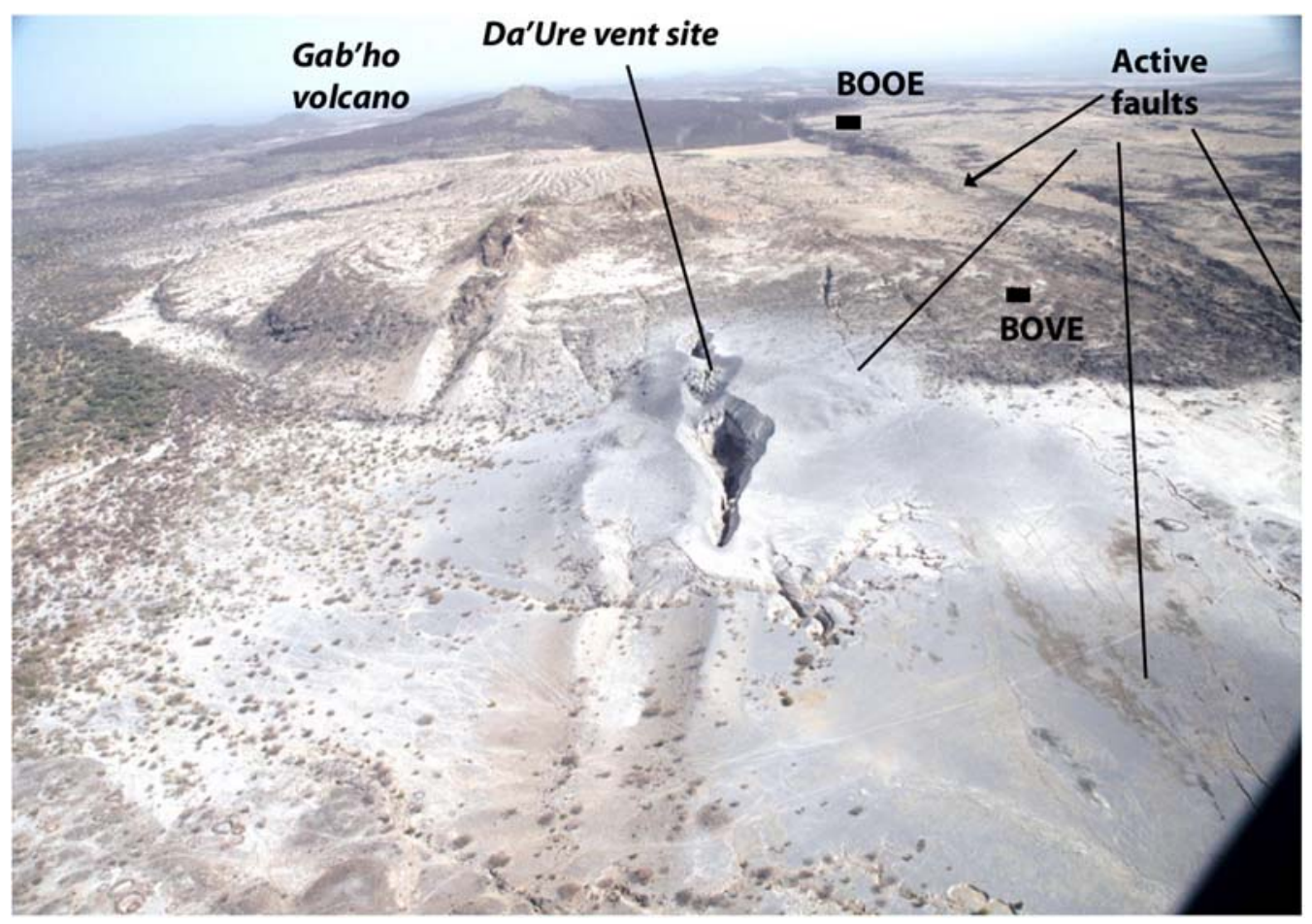

Figure 3. Aerial photo of station region. Seismic stations BOOE and BOVE are denoted by rectangles. Station BOSE is off the picture to the south. Look direction is north-northeast. Note the position of the active faults in relation to the stations as they indicate possible sources of attenuation subsurface. The arrowhead indicates the fault that slipped and emitted steam following the dike intrusion. The color version of this figure is available only in the electronic edition.

evaluate the physical properties of the intruded, faulted crust beneath this incipient seafloor spreading center.

At each of the four chosen stations (BOOE, BOVE, TERE, SILE), we measure two quantities from the spectra of each earthquake: the frequency bin containing the most energy and the fraction of total signal energy that is below $2 \mathrm{~Hz}$. Prior to measurement, the data were high-pass filtered with a fourth order Butterworth filter $(0.005 \mathrm{~Hz})$ to remove DC offsets.

Earthquakes with spectral peaks between $2-5 \mathrm{~Hz}$ and $10-12 \mathrm{~Hz}$ were observed at all seismic stations and from sources beneath Dabbahu volcano and the 2005 vent site (Fig. 4). The data lend themselves to a natural classification of LF earthquakes defined as having more than $10 \%$ of the energy below $2 \mathrm{~Hz}$. With the exception of a few, all of the LF earthquakes are hybrid with clear $P$ - and $S$-wave arrivals. At all four stations, the earthquakes produced signals with unusually long codas, lasting longer than $50 \mathrm{~s}$ for these earthquakes of magnitude less than 5 (Keir et al., 2006). These codas are observed to be dominated by frequencies around $2 \mathrm{~Hz}$. A few of the earthquakes exhibit narrow spectral peaks that could be due to resonances in a fluid-filled region (e.g., Kumagai and Chouet, 1999) or slow-slip events with long source-time functions; source functions of this class of LF earthquakes are the topic of a subsequent study using a longer time series of observation. (a) $\mathbb{N}$

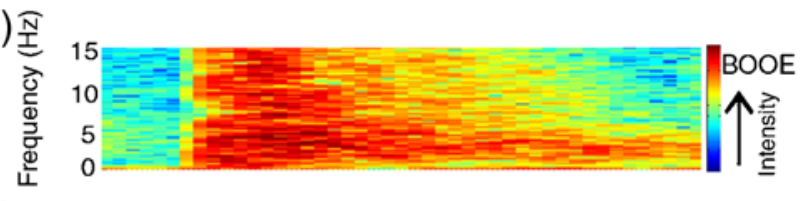

(b) $x$

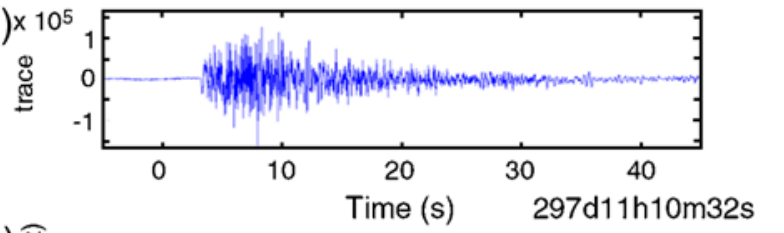

(c) 손

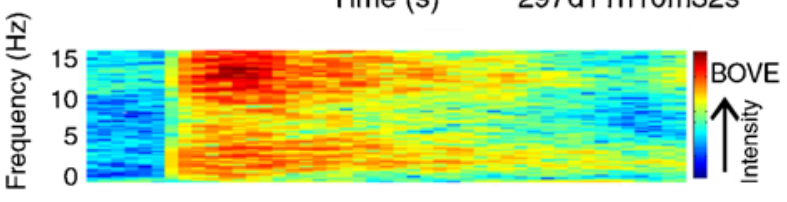

(d) $\times$

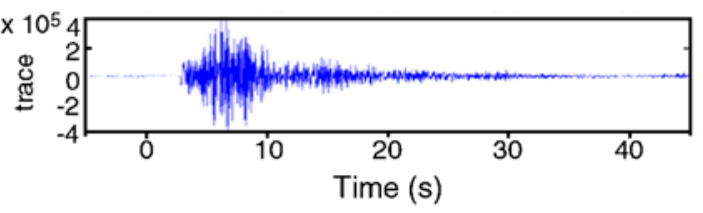

Figure 4. An $\mathrm{HF}$ earthquake from $40.4652^{\circ} \mathrm{E}, 12.5975^{\circ} \mathrm{N}$ near the center of Dabbahu as viewed at the BOVE and BOOE stations. From the top: (a) The spectrogram and (b) the $z$-velocity component trace as viewed from the BOOE site. (c) The spectrogram and (d) $z$-velocity trace as viewed from the BOVE site. We note the long LF coda is present in both signals. The color version of this figure is available only in the electronic edition. 
(a) $\stackrel{\pi}{\underline{1}}$

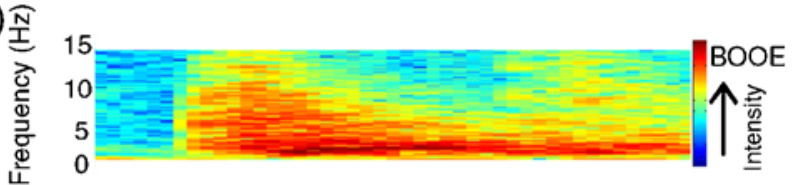

(b)

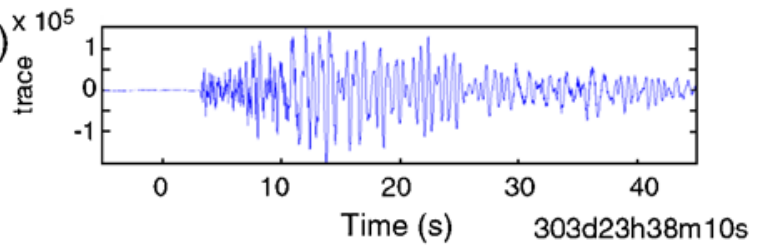

(c)

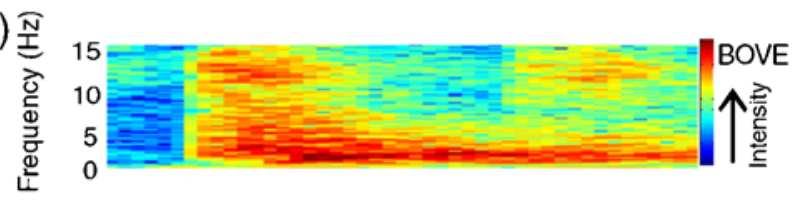

(d) $\times$

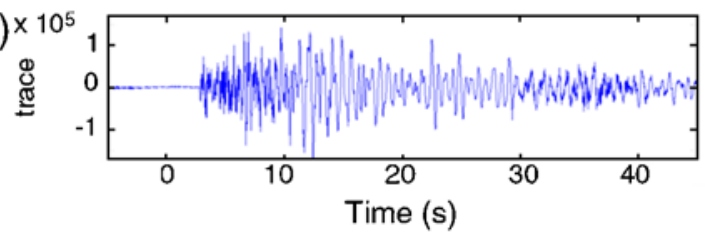

Figure 5. Similar to Figure 4 except showing an earthquake with strong LF content from $40.5433^{\circ} \mathrm{E} 12.5677^{\circ} \mathrm{N}$ on the southeast flank of Dabbahu. The signal has peak energy below $2 \mathrm{~Hz}$ at both sites and would be classified as a LF hybrid at both sites. This similarity is expected considering the back-azimuth difference between the stations for this earthquake is $3^{\circ}$. The color version of this figure is available only in the electronic edition.

Figures 4 and 5 contain spectrograms and waveforms from the vertical components for both a representative volcano-tectonic earthquake and an LF earthquake as recorded at BOOE and BOVE, respectively. To reduce bias caused by ambient HF noise, we only extend the spectrograms to $15 \mathrm{~Hz}$. Figure 5 shows a volcano-tectonic earthquake from Dabbahu with distinctly different spectra, most notably at high frequencies, as observed at BOOE and BOVE located $2 \mathrm{~km}$ to the south. The signal from the BOOE site would be classified as an LF hybrid earthquake according to the schema of McNutt (2005), as its spectrum peaks near $2 \mathrm{~Hz}$, whereas that from BOVE (only $2 \mathrm{~km}$ away with back azimuth difference of only $6^{\circ}$ for this particular earthquake) peaks near $12 \mathrm{~Hz}$ and would be classified as a volcanotectonic earthquake. At BOOE the $\mathrm{HF}$ signal is reduced significantly relative to that of BOVE, indicative of propagation through a medium preferentially attenuating high frequencies. We also note that the highest amplitude in the velocity trace is reduced by a factor of 2 at BOOE, suggesting a substantial loss of energy overall. The LF portion of the signal shows coda lengths and spectral characteristics that are similar at BOOE and BOVE sites. This is an important subtlety that we approach with care because of the known frequency dependence of attenuation coefficients (e.g., Roecker et al., 1982).
In Figure 5 we show an earthquake with peak spectral energy at a frequency below $2 \mathrm{~Hz}$ that would be classified as a LF hybrid from signals at both sites according to the classification outlined by McNutt (2005). The spectra are approximately smooth or featureless, with no strong harmonic or narrow frequency features. Thus, resonant crack models are not necessarily needed to account for the LF content. The epicenters for the earthquakes shown in Figures 4 and 5 are about $10 \mathrm{~km}$ away from BOOE and BOVE, yet over these short travel distances, the codas remain longer than $50 \mathrm{~s}$ with dominant frequencies less than $2 \mathrm{~Hz}$.

\section{Frequency Peak Distributions}

Figure 6 shows histograms of peak energy frequencies for the 805 earthquakes seen at BOVE, BOOE, TERE, and SILE sites that originate from the area beneath Dabbahu volcano. BOSE is again omitted due to difficulties in data processing because of a timing error. Seismicity was concentrated in this area so nearly all earthquakes plotted originate within $10 \mathrm{~km}$ of BOOE and BOVE. These frequency peaks are measured over a 50 -s-time window beginning $5 \mathrm{~s}$ prior to the onset of each earthquake. The BOOE site histogram displays a broad but single-peaked distribution with a maximum at about $4 \mathrm{~Hz}$. All other stations show a bimodal distribution with two peaks: one at $1-2 \mathrm{~Hz}$ and the other at $10-12 \mathrm{~Hz}$. Because the back azimuthal variation between BOOE and BOVE is small, variation in the peak frequency distributions reflects large local variations in the paths over which the waves propagate. The TERE and SILE sites also show bimodal peak frequency histograms despite their more distant locations. Even though SILE is the most distant site from the sources, there are a significant number of earthquakes from the Dabbahu area observed to have HF peaks. This implies that the HF portion of the signal is not drastically attenuated across the $\sim 70-\mathrm{km}$ travel distance to the SILE site, so the bodies affecting the signal must be located near Dabbahu.

Most interesting is the large difference seen in the frequency peak distribution between the BOVE and BOOE sites. Waveforms at BOOE show the same patterns as those at BOVE, except that the energy content of frequencies greater than $10 \mathrm{~Hz}$ is always reduced for those earthquakes to the southwest of the stations. BOVE shows bimodal distribution with a clear distinction between HF and LF earthquakes, whereas there is little division at BOOE. There is a noticeable lack of earthquakes classified in the range 4-7 $\mathrm{Hz}$ at SILE, TERE, and BOVE, whereas the majority lie within this range for BOOE. These patterns suggest that there is a natural filtering of frequencies greater than $8 \mathrm{~Hz}$ in the shallow crust beneath Dabbahu and in the dike intrusion zone between BOOE and BOVE.

Fraction of Energy Emitted below $2 \mathrm{~Hz}$. Figure 7 shows histograms of the percentage of energy emitted below $2 \mathrm{~Hz}$. These histograms can be directly compared with those 
(a)

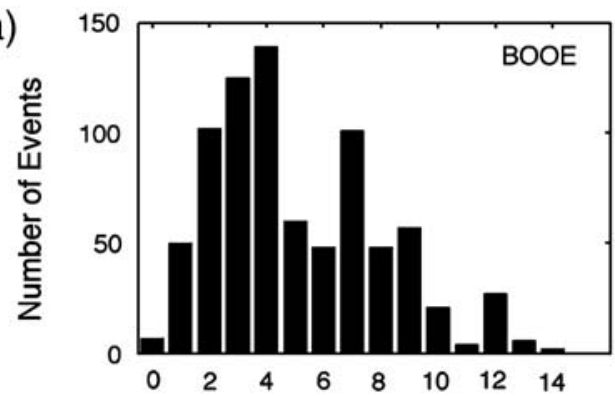

(c)

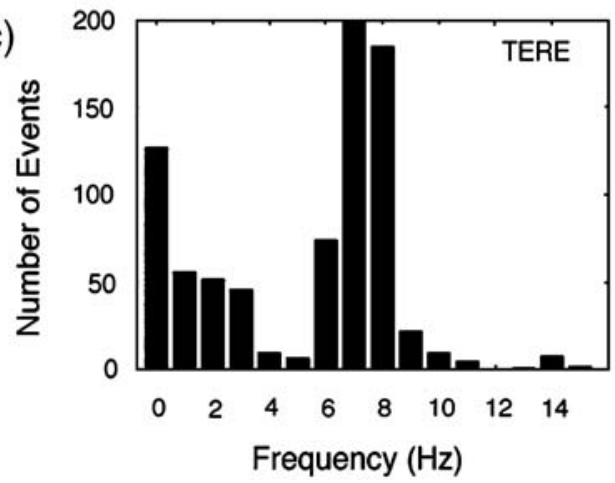

(b)

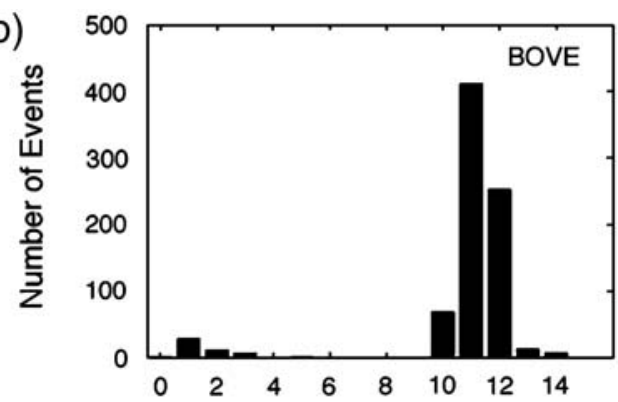

(d)

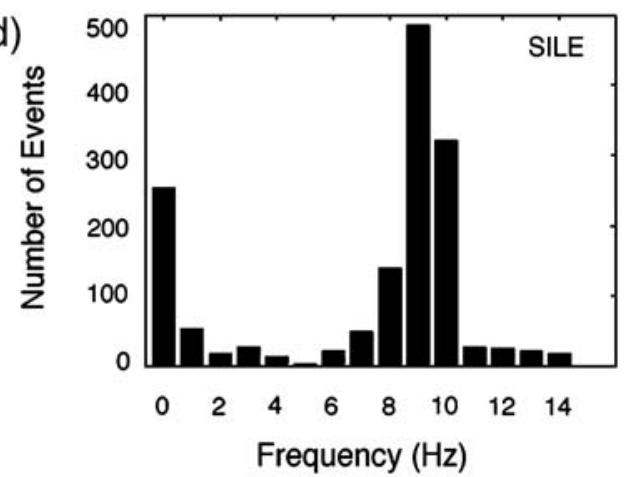

Figure 6. Histogram of frequencies of maximum energy for earthquakes between October 2005 and March 2006. (a) As seen at the BOOE site (top left). (b) As seen at the BOVE site (top right). (c) As seen at the TERE site (bottom left) (d) As seen at the SILE site (bottom right). The $y$ axis displays the number of earthquakes in a given bin and the $x$ axis shows peak frequency bins with $1 \mathrm{~Hz}$ width.

of Neuberg et al. (2000) from the Montserrat volcano region. Neuberg et al. (2000) (see their figure 3) saw a broad approximately bell-shaped histogram with peak at $50 \%$ and full width at half maximum approximately $50 \%$ energy fraction. We do not see a Gaussian distribution but a sharp peak at low energy percentages, corresponding to earthquakes with little (a)

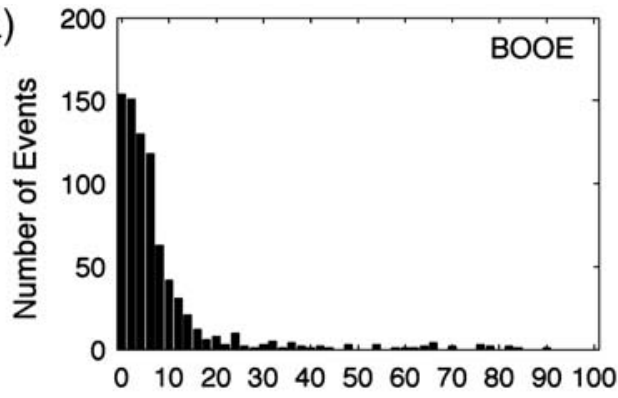

(b)

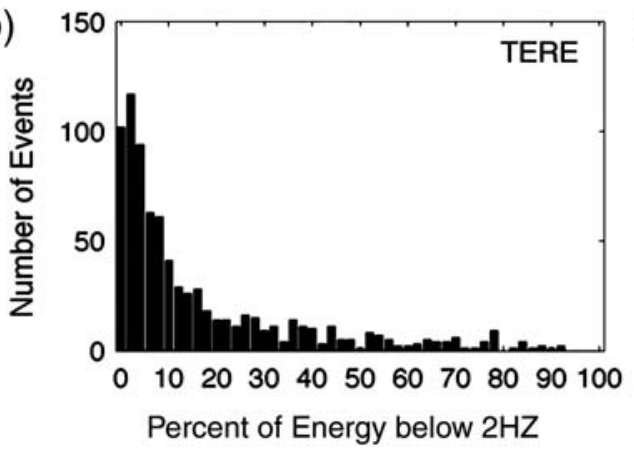

(b)

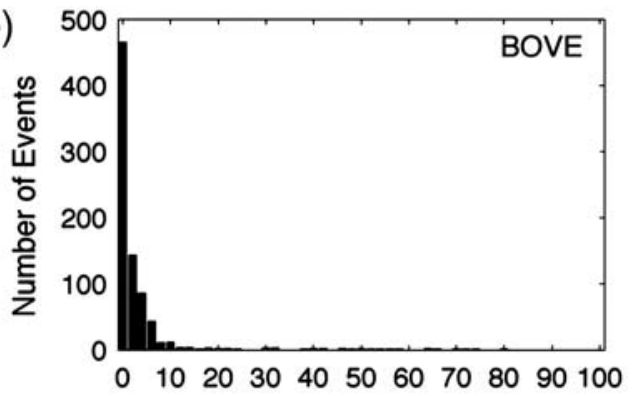

(d)

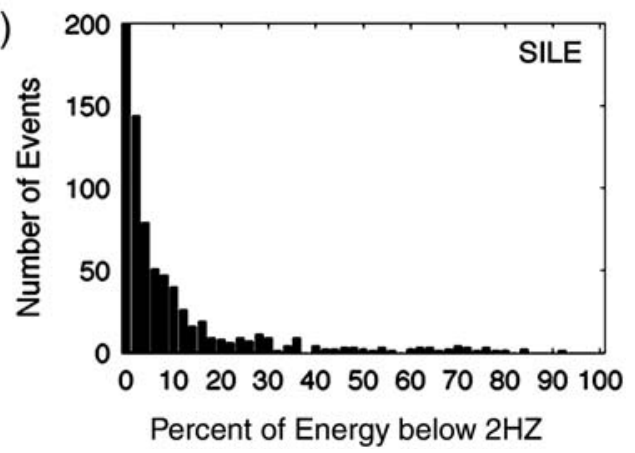

Figure 7. Histograms showing the fraction of energy below $2 \mathrm{~Hz}$ for earthquakes between October 2005 and December 2005 (a) Top left: as seen at the BOOE site. (b) Top right: as seen at the BOVE site. (c) Bottom left: as seen at the TERE site. (d) Bottom right: as seen at SILE site. The $y$ axis shows the number of earthquakes and the $x$-axis gives energy fraction below $2 \mathrm{~Hz}$ with bin widths of $2 \%$. 
LF content, and a large tail that extends to signals with a significant fraction of energy at low frequencies. The distribution has a similar shape at all stations, but the rate at which the number of earthquakes with high percentages of LF energy goes to zero varies. The most distant station (SILE) shows a much broader distribution of energy fractions. This is consistent with the progressive attenuation of high frequencies with increasing distance (Roecker et al., 1982). We conclude, as did Neuberg et al. (2000), that there is no evidence of a bimodal distribution in the energy fraction that would suggest different source mechanisms.

However, the fraction of energy at low frequencies was higher at BOOE than at BOVE, where the station overlies an unknown thickness of recent ash and pumice. The observed pattern is opposite to that expected if the ash amplifies LF surface waves.

Locations as a Function of Frequency Peak. Figure 8 shows the locations of earthquakes with LF spectral peaks compared with hybrids and tectonic earthquakes at higher frequencies. We find that most of the earthquakes with LF peaks observed at both BOOE and BOVE originate from beneath the peak of Dabbahu volcano and a zone of subsidence on its southern flank. Whereas these locations are more distant from the two sites, signals with similar spectral content to those seen at the BOVE site were seen at the TERE site, which lies southeast of Dabbahu volcano, on the opposite side of the volcano and the dike, as well as the inferred sill-like magma chamber at $\sim 3.5 \mathrm{~km}$ subsurface (Wright et al., 2006; Ebinger et al., 2008).

Both of these regions were the sites of ongoing seismicity throughout the period October-December 2005. Activity decreased in 2006, suggesting these zones fed at least some of the magma and/or gas intruded in September 2005. Thus, a small percentage of the LF earthquakes recorded at BOVE, BOOE, and TERE are associated with zones of melt where source terms may also contribute to their unusual spectral content. These events are the focus of a separate study.

Locations as a Function of Fraction of Energy below $2 \mathrm{~Hz}$. Figure 9 shows epicentral locations as a function of percentage of energy at frequencies less than $2 \mathrm{~Hz}$. BOOE site has a higher percentage of earthquakes with the largest energy fraction at frequencies less than $2 \mathrm{~Hz}$. Important to note is that the lowest frequency signals recorded at the TERE site southwest of Dabbahu volcano were nearest to Dabbahu, although most sources had energy at low frequencies. On the bottom right panel, note that the SILE site is most distant from the sources and still observed considerable energy at high frequencies from earthquakes on the southwestern side of the Dabbahu volcano. At both BOVE and SILE sites the signals with the highest LF energy were the most distant or were from the center of the swarm. We note that the depth of earthquakes ranged from 0 to $10 \mathrm{~km}$, and we found no obvious correlation between frequency peak or fraction of energy below $2 \mathrm{~Hz}$ and depth.

Observational Summary. We can summarize our comparisons between spectral characteristics and energy fractions from sites at different distances and on different sides of the dikes and magma chamber(s). The difference in peak energy and energy fraction below $2 \mathrm{~Hz}$ from the frequency histograms from the BOVE and BOOE sites implies that there are large local variations in attenuation in the diking
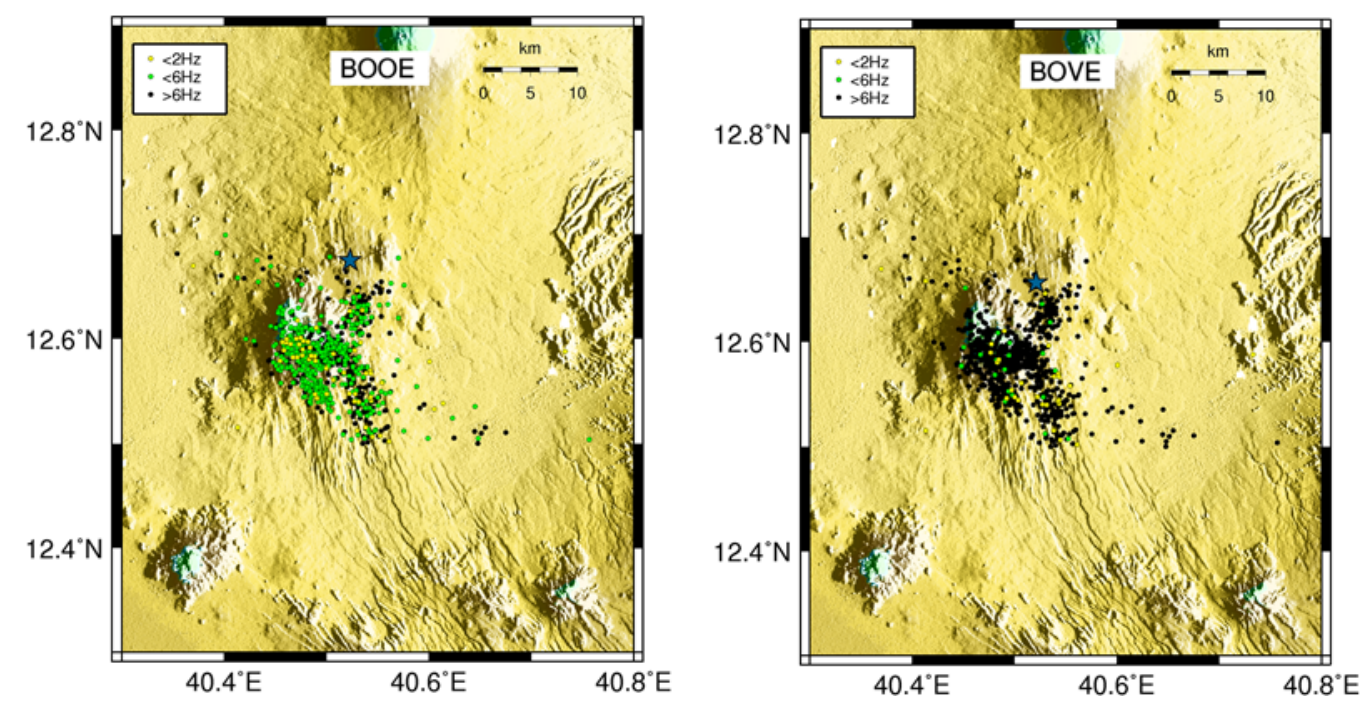

Figure 8. Earthquakes from 23 October to 29 December 2005; epicenters grouped by peak frequency. (a) The earthquakes as recorded by the station at the BOOE site, and (b) the earthquakes as recorded by the BOVE station with the station location denoted by a star. Fill indicates those earthquakes with maximum intensity at frequencies less than $2 \mathrm{~Hz}$, less than $6 \mathrm{~Hz}$, and greater or equal to $6 \mathrm{~Hz}$ as shown in the legend. The color version of this figure is available only in the electronic edition. 

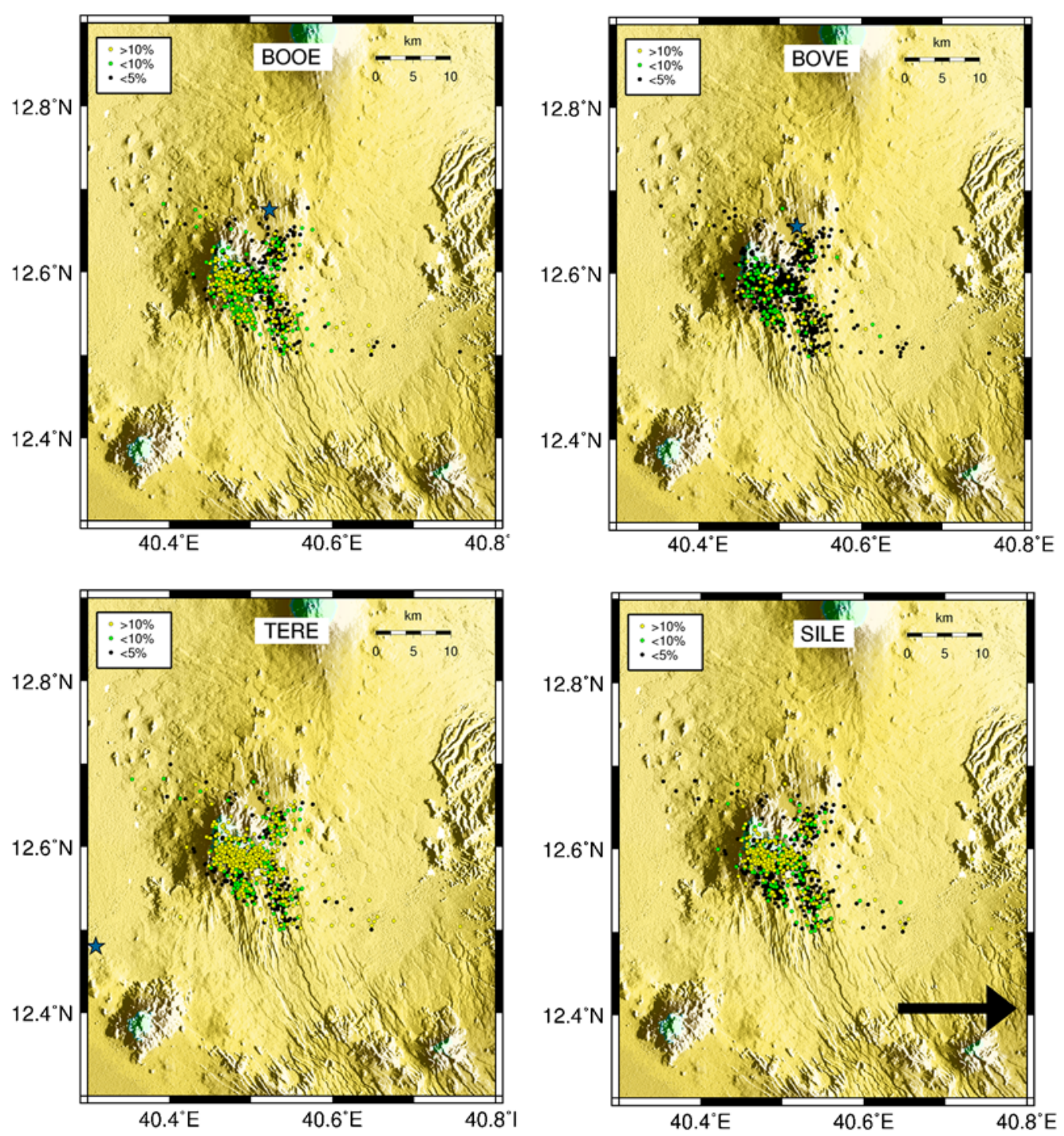

Figure 9. Epicenters according to energy percentage as observed from four sites (BOOE, BOVE, SILE, TERE) denoted in (a), (b), and (c) by a star. SILE is $2 \mathrm{~km}$ to the east of the arrowhead, off the map. Fill indicates those earthquakes with greater than $10 \%$ of their total energy below $2 \mathrm{~Hz}$, between $5 \%$ and $10 \%$ of their total energy below $2 \mathrm{~Hz}$, and less than $5 \%$ of their total energy below $2 \mathrm{~Hz}$ as shown in the legend. The color version of this figure is available only in the electronic edition.

zone separating the two stations. We find that the fraction of energy below $2 \mathrm{~Hz}$ is dependent on distance between source and sensor site with relative LF energy increasing with epicentral distance. However, signals at the TERE site had lower frequency peaks and more relative LF energy than those seen at the SILE site, which is more distant from the sources. We also find that the LF codas are remarkably long $(>50 \mathrm{~m}$ ) for the short travel distances between source and sensor site particularly for earthquakes detected at BOOE and BOVE.

\section{Attenuation and Scattering Estimates}

The dependence of the frequency peak and fraction of energy below $2 \mathrm{~Hz}$ on distance between source and station suggests that the trends we see in these two quantities may be predicted using a scattering and attenuation model. In this section we focus on the $S$-wave direct signal, and the $S$-wave coda with the goal of estimating the local scattering coefficient, $g_{0}$, and intrinsic absorption attenuation coefficient, $Q_{I}$. We will then constrain these two quantities based on the properties of $S$-wave codas in our samples.

\section{Estimate of Inverse Scattering Length}

In the absence of intrinsic absorption the incident total $S$-wave energy flux at a distance $R$ from a seismic source of total energy $W$ is

$$
F(R) \sim W / 4 \pi R^{2} .
$$

If the signal is scattered as it travels, then the direct signal (propagating on the fastest path) is attenuated by a factor 
$\exp \left\{-Q_{\mathrm{Sc}}^{-1} \omega t\right\}$, where $\omega$ is the angular frequency, $t=R V$ is the lapse time, and $V$ is the velocity of the $S$ wave. The scattering attenuation factor, $Q_{\mathrm{Sc}}^{-1}$, is related to $g_{0}$, the scattering coefficient averaged over all directions and

$$
g_{0}=Q_{\mathrm{Sc}}^{-1} k
$$

for wave vector $k$ (Frankel and Wennerberg, 1987; Sato and Fehler, 1998). The parameter $g_{0}$ is an inverse length. Thus, $g_{0}^{-1}$ is similar to a mean free path.

Scattered waves with longer travel times add to form the coda following the direct signal (Aki and Chouet, 1975). In the absence of intrinsic absorption, conservation of energy implies that the total energy flux density at a receiver (the sum of the direct signal and that in the coda) is equal to $F(R)$ (Frankel and Wennerberg, 1987). Thus, the fraction of the energy flux in the direct signal compared with the total is

$$
f_{E} \sim \exp \left\{-Q_{\mathrm{Sc}}^{-1} \omega t\right\}
$$

The energy fraction in the direct wave can be related to the scattering coefficient using equation 2

$$
g_{0}=\log f_{E} / R
$$

as intrinsic absorption is less important at low frequencies, and we have neglected energy losses in our estimate for $f_{E}$. It is best to estimate the fraction of energy of the direct wave at low frequencies. Using a coda energy fraction to estimate $Q_{\mathrm{Sc}}$ is similar to the method outlined by Korn (1988).

As the coda signal travels further and so reaches the receiver later, it can suffer additional absorption. Thus, equation 3 overestimates the fraction of energy scattered (underestimates the fraction of energy in the direct compared with the sum of the direct and scattered) and so would lead to an overestimate of the scattering inverse length, $g_{0}$.

We estimate the fraction of signal in the $S$ arrival compared with the total, $f_{E}$, from the time between the $S$-wave arrival and the time, $t_{S \text {,half }}$, it takes at low frequencies for the square of the signal to reach half the square of the $S$-wave onset amplitude. The total energy flux in the coda can be estimated by converting the half time to an exponential decay timescale $t_{e}=t_{S \text {, half }} / \ln 0.5$. We do not assume that the coda decays exponentially in time, but we do assume that the total integrated energy flux is proportional to this half time. As long as $t_{e}$ is larger than the width of the direct $S$-wave signal, then the total energy flux in the coda can be estimated as the product of the onset amplitude times $t_{e}$. Thus, the fraction of energy $f_{E}$ in the direct wave compared with the total is approximately $t_{e}$ divided by the width of the $S$-wave direct signal. Korn (1988) found a similar dependence on the estimated width of the $S$-wave direct signal.

We measure the time between the $S$-wave arrival and that where the $S$-wave coda drops to half its onset amplitude, $t_{S \text {,half }}$. This estimate ranges from 10 to $30 \mathrm{~s}$ at the BOOE site for the LF part of the wave $(\leq 2 \mathrm{~Hz})$. We estimate this from signals that have been boxcar smoothed with windows $0.5 \mathrm{~s}$ long. We estimate that the $S$-wave direct signal lasts between 0.5 and $1 \mathrm{~s}$. The ratio $f_{E}$ of energy flux in the direct wave compared with the total can be estimated from ratio of $t_{S \text {, half }}$ and is in the range $f_{E} \sim 0.01-0.07$. Most of the sources are less than $10 \mathrm{~km}$ away, implying (equation 4 ) that the scattering inverse length is in the range $g_{0} \sim 0.2-0.4 \mathrm{~km}^{-1}$. Scattering coefficients, $g_{0}$, have been estimated for a number of sites and range from 0.003 to $0.05 \mathrm{~km}^{-1}$ (figure 3.10 by Sato and Fehler, 1998 and Giampiccolo et al., 2006). The inverse scattering length scale that we estimate is high compared with those estimated from other studies in regions near volcanoes. This is expected given the multiple known magma bodies (chambers, dikes, etc.) and the recent large volume intrusion in this active rift setting.

\section{Estimate of Absorption Attenuation Coefficient}

As many have pointed out (e.g., Frankel and Wennerberg, 1987), the frequency dependence of the coda is primarily sensitive to the absorption attenuation coefficient $Q_{I}$ and less sensitive to the scattering attenuation coefficient $Q_{\mathrm{Sc}}$.

The energy density of the direct wave should be proportional to $\exp \left\{-Q_{I}^{-1} \omega t\right\}$. The fraction of energy below some frequency $\omega_{0}$ can be estimated by integrating the signal energy up to $\omega_{0}$. The spectrum of our signal can be modeled as a product of the source-time spectrum, attenuation (proportional to $\left.\exp \left\{-Q_{I}^{-1} \omega t\right\}\right)$, and a frequency and path-dependent amplification factor. If we neglect the path-dependent factor, then we can approximately assume that the fraction of energy flux below $\omega_{0}$

$$
I\left(<\omega_{0}\right) \sim \frac{\int_{0}^{\omega_{0}} \exp \left(-Q_{I}^{-1} \omega t\right) d \omega}{\int_{0}^{\omega_{c}} \exp \left(-Q_{I}^{-1} \omega t\right) d \omega},
$$

where $\omega_{c}$ is the corner angular frequency, and we have assumed that $\omega_{0}<\omega_{c}$ because we are considering only the typical volcano-tectonic earthquakes that have corner frequencies greater than $2 \mathrm{~Hz}$. We can integrate the previously mentioned estimate finding

$$
I\left(<\omega_{0}\right) \sim \frac{1-\exp \left(-Q_{I}^{-1} \omega_{0} t\right)}{1-\exp \left(-Q_{I}^{-1} \omega_{c} t\right)}
$$

which allows us to use our assumption that $\omega_{0}<\omega_{c}$ so that the denominator goes to 1 , implying

$$
I\left(<\omega_{0}\right) \sim 1-\exp \left(-Q_{I}^{-1} \omega_{0} t\right) .
$$

This predicts that strong deviations in the fraction of energy below $\omega_{0}$ only occur for $Q_{I} \omega_{0} t \sim 1$. Figure 7 shows that we do see a gradient in the fraction of energy at $2 \mathrm{~Hz}$, implying that at $2 \mathrm{~Hz}$ 


$$
Q_{I} \sim k_{0} R
$$

where $k_{0}$ is the wave vector at $\omega_{0}$.

At a frequency of $2 \mathrm{~Hz}$ and an $S$-wave travel speed of $\sim 3 \mathrm{~km} / \mathrm{s}$, the associated wavelength is $1.5 \mathrm{~km}$ and wave vector is $4 \mathrm{~km}^{-1}$. At a distance of $R \sim 10 \mathrm{~km}$ and using equation 8 , we estimate an attenuation coefficient of size $Q_{I} \sim 40$. The inverse $Q_{I}^{-1} \sim 0.02$ is also high compared with those measured from other volcanic areas (Giampiccolo et al., 2006). We can compare the size of $Q_{I}^{-1}$ to $Q_{\mathrm{Sc}}^{-1}$ at $2 \mathrm{~Hz}$ using equation 2 finding that $Q_{\mathrm{Sc}}^{-1} \sim 0.07$, similar in size to our estimated attenuation $Q_{I}^{-1}$. The similarity in size of $Q_{I}$ and of $Q_{\mathrm{Sc}}$ is measured by most studies (e.g., Giampiccolo et al. 2006). That we have also estimated a similar size for both attenuation coefficients suggests that our two estimates are self-consistent.

We note that we made our estimate for the scattering length at low frequencies assuming no absorption and then made our estimate for the absorption attenuation coefficient based on the frequency distribution finding that the absorption coefficient is high. As discussed previously, however, the estimate for the inverse scattering length scale is an underestimate and when absorption is taken into account, we should estimate an even larger scattering coefficient. Consequently, our estimate for $g_{0}$ can be considered conservative and the attenuation estimates self-consistent.

\section{Discussion}

Many of the earthquakes we have analyzed are LF hybrid earthquakes with frequency peaks at or below $2 \mathrm{~Hz}$. We find that signal frequency peak and fraction of energy below $2 \mathrm{~Hz}$ are dependent on location and station measurement site. Differences in both quantities are seen even over distances as short as $2 \mathrm{~km}$. It is likely that attenuation is higher in the vicinity of the volcano than along the ray path between the volcano and the SILE site, which preferentially samples from those waves that travel along deeper depths.

The spatial distribution of those earthquakes with relatively high LF energy suggests that attenuation is strongly dependent on position and that there are large variations in attenuation at frequencies near $2 \mathrm{~Hz}$ even across distances as small as a few kilometers. Based on the depth extent of seismicity following the dike intrusion, Ebinger et al. (2008) suggest that the dike began intrusion at a depth of 6-8 km and extended to near the surface. Thus, seismic waves from the south flank of Dabbahu would pass through the freezing dike and/or the fractured and hydrothermally altered rock above and around the dike. Considering the short path lengths and possible velocity variations beneath the rift, the differences in attenuation and scattering between BOOE and BOVE are accrued in the uppermost $1 \mathrm{~km}$. The cooling basaltic magma and high fluid pressures within fractured rock implied by the active gas venting along the faults adjacent to and above the dike could account for the increased scattering as well as attenuation between sites BOVE and BOOE.
A reflection at the fault boundary could account for the decrease in amplitude but is unlikely to account for the difference in HF energy unless there is a small-scale structure (e.g., cracks, mineralization) associated with the fault that also causes preferential attenuation of high frequencies.

Many signals exhibit long LF codas with half amplitude drop timescales in the range 10-30 s. We use the coda length timescales to estimate the fraction of energy in the direct $S$ wave arrival signal and from this estimate of the inverse scattering length. We estimate an inverse scattering length in the range of 0.1 to $0.4 \mathrm{~km}^{-1}$ at frequencies around $2 \mathrm{~Hz}$. This is a high value as indicated by comparisons with other active areas (Giampiccolo et al., 2006).

We find that the fraction of energy below $2 \mathrm{~Hz}$ increases as a function of distance between station and source even for distances as small as $10 \mathrm{~km}$. The gradient in energy fraction implies that the intrinsic absorption is strong and that frequencies around $2 \mathrm{~Hz}$ are attenuated at intermediate levels. This allows us to make an estimate of the absorption attenuation coefficient, $Q_{I}^{-1} \approx 0.02$, which is high even for a volcanic zone. However, the similarity in the sizes of our estimated scattering and attenuation coefficients is consistent with the high values of attenuation at all frequencies seen in other comparative studies and comparable to estimates from the Etna and Campi Flegrei (Vesuvius) regions (Giampiccolo et al., 2006) and the Anza region of Southern California (Frankel and Wennerberg, 1987). Giampiccolo et al. (2006) and references therein show an upper bound on $Q_{I}^{-1}$ around 0.01 in the Mount Etna region. Most of the theoretical work on scattering and attenuation models has not predicted such large amounts of scattering or attenuation over such short distances (e.g., Leary, 1995). Therefore, we conclude that near Dabbahu there is a multitude of impedance reflectors in the upper crust; a single local heterogeneity would not be sufficient to account for the long codas and would not explain the similar coda lengths at BOOE and BOVE. Thus, the attenuation coefficient estimated is also an average over a large region. It is likely that strong discontinuities such as those that are found between BOVE and BOOE exist in the region, and they could be responsible for the large local scattering and attenuation coefficients we have estimated over this region. Our analysis suggests the presence of both strong local inhomegeneities and large average scattering and attenuation coefficients over the region. This is consistent with the recent large volume intrusion creating an extensive fracture network that may contain some fluid fraction given the relatively high attenuation values.

Previous work has debated the role of path effects in affecting the frequency content of earthquakes in volcanic regions (e.g., Harrington and Brodsky, 2007; Cesca et al., 2008). The large difference in scattering and attenuation associated with a recent, faulted dike intrusion zone of width $<8 \mathrm{~m}$ observed in this paper demonstrates the importance of path effects and provides new insights into the rock damage zones adjacent to large volume intrusions. 


\section{Conclusions}

Spectral analyses of earthquakes recorded on a nearsource array deployed 3 weeks after a large volume dike intrusion and silicic eruption reveal large lateral variations in upper crustal properties, providing insights into magma intrusion processes. The recent dike intrusion and resulting fracture network are the likely causes for the high local variations observed, providing new insight into spectral content of earthquakes in areas of active volcanism.

Here we have found that scattering and attenuation inverse $Q$ coefficients are high near the Dabbahu volcano and higher than at most other locations worldwide (e.g., Giampiccolo et al., 2006). We see large differences in attenuation and scattering over length scales $<2 \mathrm{~km}$ and with no significant change in azimuth, which we attribute to the presence of melt and gas-filled cracks above, beside, and within the dike injection zone. The long coda lengths require multiple scattererers along the $10-\mathrm{km}$ path lengths, consistent with independent constraints on the distribution of active magma bodies. With these constraints on path effects, future work will examine the source terms of ongoing earthquake swarms from Dabbahu volcano, as well as the 12 subsequent dike intrusions that have occurred since September 2005.

\section{Data and Resources}

Analyses in this work were supported in part by National Science Foundation (NSF) grants PHY-0552695, Natural Environment Research Council (NERC) fellowship grant number NE/E013945/1, and EAR0635789. Field work was supported by NERC grant NE/D008611/1, GEF loan 803, the Ministry of Capacity Building (Ethiopia), the Afar government.

\section{Acknowledgments}

Thank you to James Hammond, Elias Lewi, Gezahegn Yirgu, Roger Buck, John Elliott, Alex Brisbourne, and Anna Horleston for their help with data acquisition. This work also would not have been the same without the help of Connie Jones in her role in as administrator in the Research Experience for Undergraduates program at the University of Rochester. We would also like to thank two anonymous reviewers and Steve McNutt for valuable input during the preparation of the manuscript. This material is based upon work supported in part by the National Science Foundation Grant Number PHY-0552695.

\section{References}

Aki, K. (1992). State of the art in volcano seismology, Volcanic Seismology, P. Gasparini, R. Scarpa, and K. Aki (Editors), Springer-Verlag, Berlin, $3-10$.

Aki, K., and B. Chouet (1975). Origin of coda waves: Source, attenuation and scattering effects, J. Geophys. Res. 80, 3322-3342.

Aki, K., M. Fehler, and S. Des (1977). Source mechanism of volcanic tremor: Fluid-driven crack models and their application to the 1963 Kilauea eruption, J. Volcanol. Geoth. Res. 2, 259-287, doi 10.1016/0377-0273(77)90003-8.

Ayele, A., E. Jacques, M. Kassim, T. Kidane, A. Omar, S. Tait, A. Nercessian, J.-B. de Chabalier, and G. King (2007). The volcano-seismic crisis in Afar, Ethiopia starting September 2005, Earth Planet. Sci. Lett. 48, 70-79.

Ayele, A., D. Keir, C. Ebinger, T. Wright, G. Stuart, W. R. Buck, E. G. Jacques, G. Ogubazghi, and J. Sholan (2009). September 2005 mega-dike emplacement in the Manda-Harraro nascent oceanic rift (Afar Depression), Geophys. Res. Lett. 36, L20306, doi 10.1029/2009GL039605d.

Barberi, F., and J. Varet (1977). Volcanism of Afar: small-scale plate tectonic implications, Geol. Soc. Am. Bull. 88, 1251-1266.

Brandsdóttir, B., and P. Einarsson (1992). Volcanic tremor and lowfrequency earthquakes, in Iceland in IVACEI Proceedings in Volcanology P. Gasparini, R. Scarpa, and K. Aki (Editors), 212-222, SpringerVerlag, New York.

Cesca, S., J. Battaglia, T. Dahm, E. Tessmer, S. Heimman, and P. Okubo (2008). Effects of topography and crustal heterogeneities on the source estimation of LP event at Kilauea volcano, Geophys. J. Int. 172, 1219-1236.

Chouet, B. A. (1996). Long-period volcano seismicity: Its source and use in eruption forecasting, Nature 380, 309-316.

Chouet, B. A. (2003). Volcanoseismology, Pure Appl. Geophys. 160,739-788.

Ebinger, C. J., D. Keir, A. Ayele, T. J. Wright, M. Belachew, J. O. S. Hammond, M. E. Campbell, and W. R. Buck (2008). Capturing magma intrusion and faulting processes during continental rupture: Seismicity of the Dabbahu (Afar) rift, Geophys. J. Int. doi 10.1111/ j.1365-246X.2008.03877.x.

Frankel, A., and L. Wennerberg (1987). Energy flux model of seismic coda: Separation of scattering and intrinsic attenuation, Bull. Seismol. Soc. Am. 77, 1223-1251.

Giampiccolo, E., T. Tuvey, S. Greast, and D. Patane (2006). S-waves attenuation and separation of scattering and intrinsic absorption of seismic energy in southeastern Sicily (Italy), Geophy. J. Int. 165, 211-222.

Grandin, R., A. Socquet, R. Binet, Y. Klinger, E. Jacques, J.-B. De Chabalier, G. C. P. King, C. Lasserre, S. Tait, P. Tapponnier, A. Delorme, and P. Pinzuti (2009). September 2005 Manda Hararo-Dabbahu rifting event, Afar (Ethiopia): Constraints provided by geodetic data, J. Geophys. Res. 114, B08404, doi 10.1029/2008JB005843.

Harrington, R. M., and E. E. Brodsky (2007). Volcanic hybrid earthquakes that are brittle-failure events, Geophys. Res. Lett. 34, L06308, doi 10.1029/2006GL028714.

Keir, D., A. Ayele, E. Calais, I. Hamling, C. Ebinger, T. J. Wright, E. Jacques, M. Kassim, J. O. S. Hammond, M. Belachew, E. Baker, and J. Rowland (2009). Evidence for focused magmatic accretion at segment centers from lateral dike injections captured beneath the Red Sea rift in Afar, Geology 37, 59-62, doi 10.1130/G25147A.1.

Keir, D., G. W. Stuart, A. Jackson, and A. Ayele (2006). Local earthquake magnitude scale and seismicity rate for the Ethiopian Rift, Seismol. Soc. Am. 96, 2221-2230 doi 10.1785/0120060051.

Klein, F. W. (2002). User's guide to Hypoinverse-2000, a FORTRAN program to solve for earthquake locations and magnitudes, U.S. Geol. Surv. Open-File Rept, 02-171, 1-123.

Korn, M. (1988). $P$-wave coda analysis of short-period array data and the scattering and absorptive properties of the lithosphere, Geophys. J. Int. 93, 437-449.

Kumagai, H., and B. A. Chouet (1999). The complex frequencies of longperiod seismic events as probes of fluid composition beneath volcanos, Geophys. J. Int. 138, F7-F12.

Lahr, J. C., B. A. Chouet, C. D. Stephens, J. A. Power, and R. A. Page (1994). Earthquake classification, location, and error analysis in a volcanic environment: Implications for the magmatic system of the 1989-1990 eruptions at Redoubt Volcano, Alaska, J. Vol. Geotherm. Res. 62, 137-151.

Leary, P. C. (1995). Quantifying crustal fracture heterogeneity by seismic scattering, Geophys.. J. Int.. 122, 125-142.

McNutt, S. R. (2005). A review of volcanic seismology, Ann. Rev. Earth Planet Sci. 33, 461-491, doi 10.1146/annurev.earth.33.092203.122459.

Neuberg, J. W., H. Tuffen, L. Collier, D. Green, T. Powell, and D. Dingwell (2006). The trigger mechanism of low-frequency earthquakes on Montserrat, J. Vol. Geotherm. Res. 153, 37-50. 
Neuberg, J., R. Luckett, B. Baptie, and K. Olsen (2000). Models of tremor and low-frequency earthquake swarms on Montserrat, J. Vol. Geotherm. Res. 101, 83-104.

Roecker, S. W., B. Tucker, J. King, and D. Hatzfield (1982). Estimates of $Q$ in central Asia as a function of frequency and depth using the coda of locally recorded earthquake, Bull. Seismol. Soc. Am. 72, $129-149$.

Rowland, J. V., E. Baker, C. J. Ebinger, D. Keir, T. Kidane, J. Biggs, N. Hayward, and T. J. Wright (2007). Fault growth at a nascent slow-spreading ridge: 2005 Dabbahu rifting episode, Afar, Geophys. J. Int. 171, 1226-1246, doi 10.1111/j.1365-246X.2007.03584.x.

Sato, H., and M. C. Fehler (1998). Seismic Wave Propagation and Scattering in the Heterogeneous Earth, Springer-Verlag, New York.

Turcotte, D. L., and G. Schubert (2002). Geodynamics, Second Ed., Cambridge University Press, New York.

Waldhauser, F., and W. Ellsworth (2000). A double-difference earthquake location algorithm: Method and application to the northern Hayward fault, California, Bull. Seismol. Soc. Am. 90, 1353-1368.

Wright, T. J., C. Ebinger, J. Biggs, A. Ayele, G. Yirgu, D. Keir, and A. Stork (2006). Magma-maintained rift segmentation at continental rupture in the 2005 Afar dyking episode, Nature 442, 291-294, doi 10.1038/ nature 04978 .

Yirgu, G., A. Ayele, and D. Ayalew (2006). Recent seismo-volcanic crisis in northern Afar, Ethiopia, Eos Trans. Am. Geophys. Un. 87, 325-336.
Department of Earth and Environmental Sciences

University of Rochester

Rochester, New York 14627

(D.M.C., M.B., C.J.E.)

Department of Physics and Astronomy

University of Rochester

Rochester, New York 14627

(A.C.Q.)

School of Earth and Environmental Sciences

University of Leeds

Leeds, England, LS2 9JT

(D.K., T.W.)

Institute of Geophysics, Space Science, and Astronomy

Addis Ababa University

PO Box 1176

Addis Ababa, Ethiopia

(A.A.)

Manuscript received 4 May 2009 